\title{
The Librarian, the Machine, or a Little of Both: A Comparative Study of Three Information Literacy Pedagogies at Oakland University
}

\section{Elizabeth W. Kraemer, Shawn V. Lombardo, and Frank J. Lepkowski}

\begin{abstract}
Each year, Oakland library faculty provide information literacy instruction for Rhetoric 160, a first-year writing course, through a combination of WebCT-based online tutorials and in-class teaching. For this study, twelve sections of RHT 160 during the winter 2005 term were selected to compare three instructional methods: online instruction only, live instruction, and the current "hybrid" combination of live instruction and online tutorials. The sections were assigned to one of the instructional methods and, to assess student learning, all students $(n=224)$ completed identical pre- and post-tests. Results of the study, including differences in student performance in relation to pedagogy, are discussed.
\end{abstract}

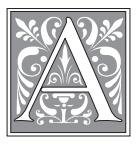

t Oakland University (OU), a doctoral institution of 17,000 students in Rochester, Michigan, course-integrated library instruction for freshman composition is a long-standing joint commitment between the faculty from the Department of Rhetoric, Communication and Journalism and those at Kresge Library. The goal of this partnership is to introduce students to the library research process early in their academic careers. In a busy instruction program that has reached approximately one-third of the total student population in recent years, information literacy instruction for Rhetoric 160: Composition II (RHT 160) comprises about half of the total teaching load of the library.

Oakland University's student population has grown by more than 40 percent over the past 20 years. ${ }^{1}$ Unfortunately, while the library's instructional load has had to increase to keep pace with enrollment, the number of library faculty actually has diminished over the same time period, leaving fewer librarians to teach more instruction sections. As a result, librarians at OU found it difficult to maintain the traditional full-week's worth of instruction for RHT 160 students, even as the increasingly complex process of finding and retrieving sources called for more, not less, instructional

Elizabeth W. Kraemer is Assistant Professor, Shawn V. Lombardo is Associate Professor, and Frank J. Lepkowski is Associate Professor in the Kresge Library at Oakland University; e-mail: kraemer@oakland. edu, lombardo@oakland.edu, and lepkowsk@oakland.edu, respectively. The authors gratefully acknowledge Patrick Howell, MLIS, for his assistance with the statistical analysis in this study. 
time. By 2000, the library had reached a breaking point.

At about this time, Oakland University administrators were promoting to faculty the use of the WebCT course management online system. In 2001, the library decided to supplement information literacy instruction with an online library instruction module that students could access by logging into their RHT 160 course in WebCT. By presenting some material online in this fashion, librarians were able to reduce the number of contact hours with each section of RHT 160. A series of tutorials and quizzes in this online module covered the physical layout of the library, essential policies and procedures, and the basics of searching the Voyager online catalog; after completing these tutorials, the RHT 160 classes received two contact hours of instruction from a librarian. A pretest and post-test in the WebCT module allowed for some assessment of student learning.

The transition to this hybrid instructional model was accompanied by a great deal of apprehension among members of the library faculty. Some librarians felt that its rigid tutorials and multiple-choice questions would be no substitute for personal instruction; others felt that the basics of library information and procedures could be taught successfully online. Still others thought that library instruction for RHT 160 could be presented completely via WebCT, thus freeing up librarian time for other purposes.

From this internal debate, based on librarians' deeply held commitment to teaching research skills to students at Oakland University, the present study was conceived and conducted. Specifically the investigators wished to answer the following questions:

Research Question 1: Does library instruction, regardless of format, improve student learning outcomes?

Research Question 2: Does the format of library instruction impact student learning outcomes?
Research Question 3: Does instruction method affect students' satisfaction with their library instruction?

Research Question 4: Does instruction method influence students' assessment of their own research abilities?

The following study reports on the first year of an ongoing project to address these areas of inquiry.

\section{Literature Review \\ Advantages and Drawbacks of Computer- Assisted Instruction}

Computer-assisted instruction (CAI) describes the use of computers to teach students without the intercession of a human instructor. A review of the literature reveals over and over again that often libraries turn to some form of CAI to help manage one inescapable problem: the growing need for library instruction outpaces the capabilities of overstretched staff at many institutions. ${ }^{2}$ Beyond that, CAI can also be used to allay librarian burnout, as noted by Dixon and colleagues at the University of Tennessee, Knoxville: "Even with changes over the years, maintaining the enthusiasm necessary to make the classes interesting became increasingly difficult." ${ }^{3}$ Computer-assisted instruction has also been used to standardize the library instruction given to students. ${ }^{4}$

In addition to the benefits that can be gained by libraries and librarians, CAI holds a number of advantages for students as well, all of which can improve understanding and retention of the material presented in electronic tutorials. First, computer-assisted instruction "offers an alternative learning approach that may be appealing to students who have experienced only the lecture method." ${ }^{5}$ Several authors have also praised the opportunity to integrate "bells and whistles" into CAI tutorials to keep students' interest;, ${ }^{6}$ similarly, the interactivity that can be worked into electronic tutorials helps maintain focus and attention by allowing students to individualize their learning experiences. ${ }^{7}$ Instruction developers also laud the fact that in a CAI environment, users can work 
through the lessons at their own speed. ${ }^{8}$ Author Don Tapscott endorses this feature from the student perspective, commenting of his own experience in an online class: “...unlike traditional courses, I could stop and review something I didn't understand or fast-forward through material I felt I had grasped." ${ }^{\prime 9}$ Another significant benefit to the student is the opportunity for contact with technology; in fact, in outlining the ways in which CAI lends itself to library instruction, Ann Turner notes, "Using the computer to teach computer skills is an efficient approach." ${ }^{10}$

Offering online library instruction in a courseware environment can add yet another layer of usability to an instructional program. Major advantages of course management tools such as WebCT or Blackboard are the data storage and analysis features of these tools, which allow researchers to track completion rates and grades all in one place. ${ }^{11}$ Additionally, courseware allows for built-in student evaluation and immediate feedback on quizzes and tests, which allows students to check their progress. ${ }^{12}$

While CAI provides a number of benefits, libraries have repeatedly reported on problems arising from the addition of computer-assisted instruction to their teaching programs. One concern of librarians and teaching faculty alike is the fact that CAI tends to reduce personal contact time between student and librarian. ${ }^{13}$ Students may also lose the chance to connect with "the physical and social space of the library." ${ }^{14}$ These losses may result in students feeling uncomfortable coming to the library or approaching librarians to ask for help when needed.

Finally, research shows that the success of computer-assisted instruction depends in large part on the motivation of students: many libraries have found that if students do not receive some form of external motivation - such as a class requirement or an assignment grade - to complete the electronic component of a library instruction program, the majority of students simply will not do it. ${ }^{15}$ One study further suggests that students' isolation while working through the electronic library instruction tutorial may negatively impact their motivation and attitude. ${ }^{16}$

\section{How Does CAI Fare Against Other Teaching Methods?}

For years, institutions have conducted studies comparing the effectiveness of computer-assisted instruction to more traditional modes of delivery. Most studies comparing computer-assisted instruction to librarian-led sessions find few significant differences in post-test performance between instructional formats. ${ }^{17}$

For example, Germain, Jacobson, and Kaczor compared the effectiveness of a Web-based module to that of live instruction at the University of Albany for the students in the first-year experience program there. Using an identical preand post-test, the researchers compared outcomes for each teaching method with a sample size of 284 students. They found no significant difference in post-test mean scores between Web-based and live instruction, indicating that both delivery methods were equally effective. Due to the results of their study, the authors decided to use the Web-based tutorial for library instruction, but to have students complete it in class under the guidance of their classroom teacher. ${ }^{18}$ In a similar study, conducted at SUNY Oswego, Nichols, Shaffer, and Shockey found no significant difference in either student satisfaction or performance regardless of instruction format. ${ }^{19}$

Dissenting results were found in the study conducted by Marion Churkovich and Christine Oughtred at Deakin University. In this study, which included 174 first-year sociology students, the researchers sought to determine if an online tutorial could be used to successfully train students without the presence of a librarian. One distinct difference in this institution's approach was the purchase of a customized online instruction tool rather than in-house tutorial design. Students were randomly assigned to one of 
three instruction methods: independent online tutorial completion, librarianmediated online tutorial completion, or traditional face-to-face instruction with a librarian. The researchers were surprised to find that the face-to-face group showed significantly greater improvement from pre-test to post-test over the other two methods of instruction. Additionally, they found that students completing the tutorial independently were less confident after library instruction than students in the other two groups. Churkovich and Oughtred concluded that "contact with and instruction by a librarian is desirable for the best learning outcomes and confidence in development of information literacy skills." ${ }^{20}$ Based on the findings of this study, the librarians at Deakin University planned to continue to use face-to-face instruction for subject-specific classes, while relying on an updated version of the online tutorial only to teach basic catalog skills training to First Year Introduction Program students. ${ }^{21}$

Very few studies have examined the effectiveness of library instruction specifically delivered via course management software. One such study was conducted in 1998 at Western Kentucky University, where online library instruction delivered via WebCT was compared to classroom instruction for a one-credit library research skills course. ${ }^{22}$ Study participants self-selected their groups, as 45 students registered for the traditional group and 43 enrolled in the Web group for a total sample size of 88 people. Web students were not required to come to campus to complete the work, but had access to their instructor via e-mail if needed. The researchers, Linda B. Alexander and Robert C. Smith, chose a causal-comparative model for this study, using only a post-test to measure student performance. T-test comparisons for the two groups showed no significant difference on post-test scores, which suggests that the quality of the two instructional formats was very similar. In a comparison of ratings of activities and resources by students in each group, Web students consistently indicated more positive attitudes in how beneficial they found the course to be. Further analysis of the data displayed a higher preference among nontraditional students than traditional students for Web-based courses.

\section{Methodology \\ Study Design}

The target population for this study consisted of students enrolled in Rhetoric 160: Composition II (RHT 160) at Oakland University for the 2005 winter semester. The researchers opted to conduct a threeway comparative study of pedagogical methods based upon the library's current RHT 160 instructional model. ${ }^{23}$ To facilitate this model, four faculty members from the Department of Rhetoric, Communication and Journalism, teaching three sections each that term, agreed to have their classes participate in the study. Each instructor's three RHT 160 sections were randomly assigned to receive library instruction using one of three delivery formats: all-online using WebCT; a hybrid of face-to-face and online; and all-live instruction by a librarian. Numerous studies have shown that library instruction, regardless of format, improves student performance; ${ }^{24}$ therefore, the authors elected not to employ a noninstructional control group in this study. In an effort to avoid variation in student performance due to differing instructional styles among the three librarians conducting the study, it was determined that one librarian would work with all sections for a particular Rhetoric instructor. Random assignments of librarian to instructor were made early in the winter semester.

The authors received approval from Oakland University's Institutional Review Board (IRB) in late 2004 to undertake the project. In February of 2005, the authors visited the classes to which they were assigned in order to outline the study and distribute the study guidelines and consent forms. Students who did not turn in signed consent forms were still required 


\begin{tabular}{|l|c|c|c|c|}
\hline \multicolumn{5}{|c|}{ TABLE 1 } \\
\hline & $\begin{array}{c}\text { Non } \\
\text { experimental }\end{array}$ & Hybrid & Face-to-face & Online \\
\hline \hline Pre-Test & $\mathrm{X}$ & $\mathrm{X}$ & $\mathrm{X}$ & $\mathrm{X}$ \\
\hline Library Virtual Tour & $\mathrm{X}$ & $\mathrm{X}$ & & $\mathrm{X}$ \\
\hline Top Ten Facts & $\mathrm{X}$ & $\mathrm{X}$ & & $\mathrm{X}$ \\
\hline Voyager Basics & $\mathrm{X}$ & $\mathrm{X}$ & & $\mathrm{X}$ \\
\hline Keyword Searching & & & & $\mathrm{X}$ \\
\hline Evaluating Periodicals & & & & $\mathrm{X}$ \\
\hline FirstSearch & & & & $\mathrm{X}$ \\
\hline InfoTrac & & & & $\mathrm{X}$ \\
\hline LexisNexis & $\mathrm{X}$ & $\mathrm{X}$ & $\mathrm{X}$ & $\mathrm{X}$ \\
\hline Post-Test & & & & \\
\hline
\end{tabular}

to complete the course of bibliographic instruction, with the understanding that their scores would not be included in the study. The study began with 247 subjects in the twelve experimental sections. Subjects were required to complete all assigned quizzes and to attend all assigned instruction sessions; students who did not complete all of the requirements of their library instruction model were eliminated from the study. The final sample consisted of 224 students, distributed approximately equally into the three instructional groups - live, hybrid, and online. In addition, data were available for comparative purposes from 963 students from all other sections of RHT 160 who completed their library instruction during the winter 2005 semester. All subjects in this group, labeled the nonexperimental group in table 1 , received their library instruction via the typical hybrid instruction model.

\section{Procedure}

Table 1 illustrates the content that was conveyed via WebCT for the three experimental versions of RHT 160, as well as the nonexperimental sections; note that the mixed instructional model for the hybrid experimental sections was the same as that of all the nonexperimental sections for the semester.
Instructional content was delivered to students either in the classroom or online through Web-based tutorials that were accessed via WebCT. The tutorials were designed to deliver as closely as possible both the information and hands-on opportunities experienced by those students working with a librarian. For example, the FirstSearch, InfoTrac, and LexisNexis tutorials were constructed in a split-screen format, allowing students to conduct live searches in the database while reading instructions and tips in a separate frame, as illustrated in figure 1.

The students in the experimental groups, regardless of instructional method, met in a library computer classroom over the course of a week. Subjects assigned to the live group attended a total of three hours of library instruction, which combined librarianled demonstrations and lectures with active learning exercises that students completed in class. Subjects in the hybrid group first completed their Web-based instruction via WebCT, then attended two hours of instruction by a librarian. Finally, the online group completed all of their instruction-consisting of eight online tutorials and accompanying quizzes-in WebCT. Students in the online group completed all of their work in the 
computer classroom, and a librarian was available to address technological issues; however, neither the librarian nor the Rhetoric instructor answered questions about the content of the tutorials. For the hybrid and online groups, quizzes followed each tutorial in WebCT; these quizzes measured student understanding of the tutorial and also permitted them access to the next quiz within WebCT.

All study subjects completed an identical 15-point pre-test and final exam (posttest) in WebCT. Success of instruction was measured by matching pre-test and final exam scores for each student.

\section{Results}

The data were analyzed using the SPSS statistical package, and a significance level of .05 was chosen because of its widespread acceptance in data analysis. The mean scores on the pre-test and final exam for each of the experimental samples, as well as the nonexperimental group, are included in table 2; as illustrated in the table, the live group scored highest on both the pre-test and the final exam, although final exam performance for the live and hybrid groups appears almost indistinguishable from one another. A one-way analysis of variance (ANOVA) of pre-test scores, conducted to identify baseline disparities among the instructional groups prior to instruction, did not reveal any initial significant difference among the group means $(\mathrm{F}=1.888$, $\mathrm{p}=.154$ ). In addition, the researchers performed a t-test of independent samples to compare the pre-test and final exam results of the entire experimental sample $(\mathrm{N}=224)$ with the nonexperimental group $(\mathrm{N}=963)$. For both the pre-test $(\mathrm{t}=.845$, $\mathrm{p}=.399)$ and the final exam ( $\mathrm{t}=1.529$, $\mathrm{p}=.127)$, no significant differences in the means were found, suggesting that performance on the pre-test and final exam was not impacted by subject involvement in the study.

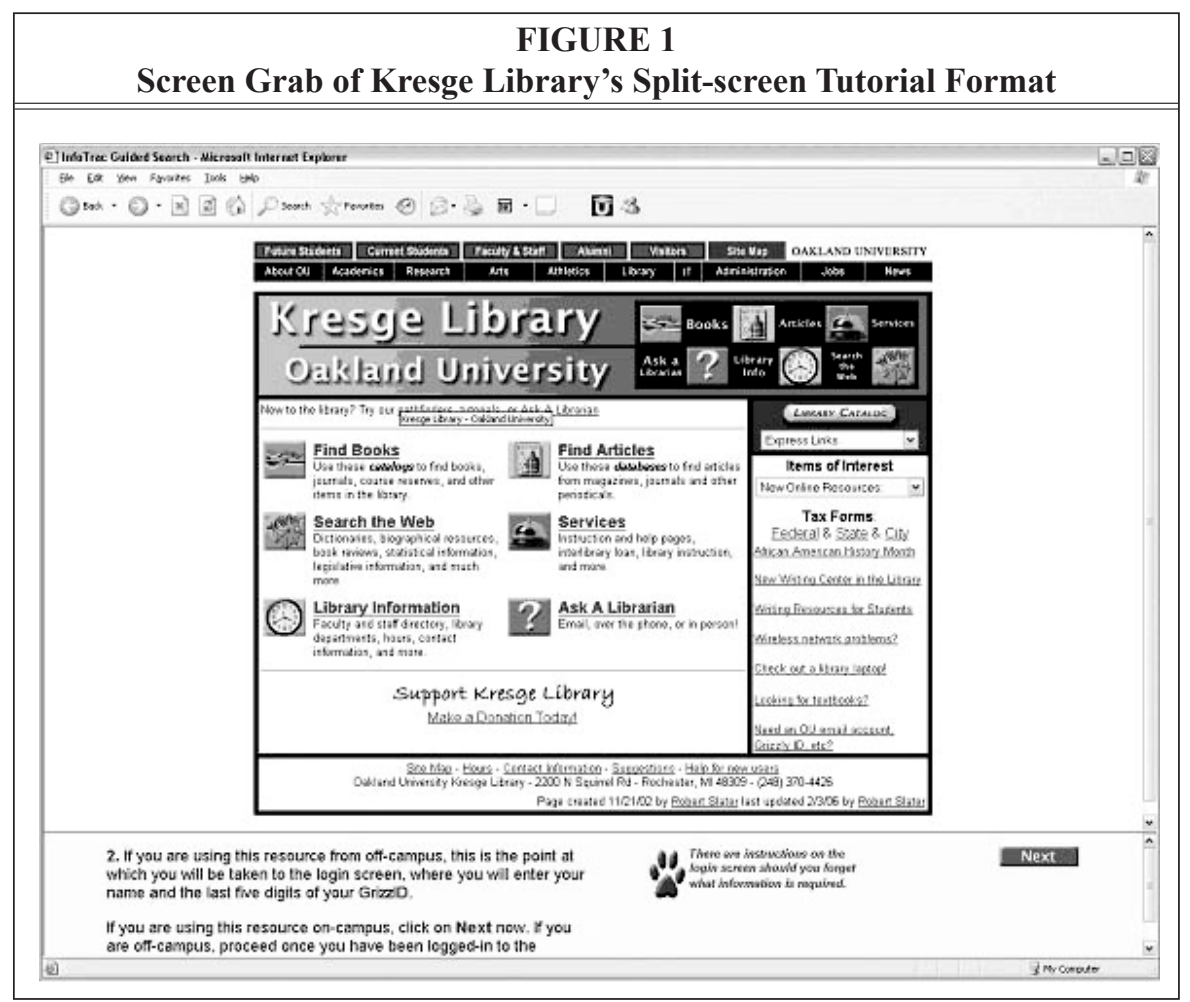




\section{Research Question One: Does Library Instruction, Regardless of Format, Improve Student Learning Outcomes?}

For the entire experimental group, 76.8 percent of the subjects showed improvement from their pre-test to final exam scores. Another 15.2 percent scored the same on each test, and the final 8.0 percent of students actually scored lower on the final exam following library instruction than they had on the pre-test. A paired-samples t-test performed on the entire experimental group revealed that, overall, students in the experimental group showed significant improvement $(\mathrm{t}=15.403, \mathrm{p}=.000)$ in their test performance.

The researchers also conducted pairedsamples t-tests on the three instructional groups to determine if significant improvement in test performance occurred for each sample following library instruction. For all of the experimental groups, the average improvement in test scores after students completed their library instruction was 1.906 points; the hybrid group showed the greatest improvement in scores, with a mean difference of 2.278 points. For each of the samples, table 2 contains the difference in means between the pre-test and final exam scores as well as the $t$-values generated from the pairedsamples t-test; as indicated in the table, the $\mathrm{t}$-values for all of the experimental groups were found to be significant at the .000 confidence level. Therefore, the researchers conclude with a high degree of con- fidence that significant improvement in test performance occurred for all subjects following library instruction, regardless of the format of that instruction.

A correlation analysis was conducted as well, to investigate the relationship between pre-test and final exam scores. Table 2 provides the Pearson's correlation coefficient (r) for each of the samples. With the exception of the hybrid group, all groups displayed a significant positive correlation between pre-test and final exam scores; that is, students who scored high on the pre-test tended to score high on the final exam. Data from the hybrid group was explored more closely to identify possible causes for the lack of significant positive correlation between pre-test and final exam scores for these subjects. A scatterplot of the pre-test and final exam results for the hybrid group reveals a number of students whose scores improved drastically following library instruction: these students scored well below the mean on the pre-test and well above the mean on the final exam, adding support to the finding above that the hybrid group showed the greatest improvement in test scores. Although subjects did not know their scores on the exams until after the final exam was completed, the lack of correlation of test scores for the hybrid group may indicate a higher level of motivation or engagement during their library instruction, or it may indicate that some of these students were

\begin{tabular}{|l|r|r|r|r|c|c|}
\hline \multicolumn{7}{|c|}{ TABLE 2 } \\
\hline & Paired Samples T-Tests: Exam Results & $\begin{array}{c}\text { Pre-test } \\
\text { Mean }\end{array}$ & $\begin{array}{c}\text { Final } \\
\text { Exam } \\
\text { Mean }\end{array}$ & $\begin{array}{c}\text { Difference } \\
\text { of Means }\end{array}$ & r & t \\
\hline All experimental sections & 224 & 10.795 & 12.700 & 1.906 & $.391^{*}$ & $15.403^{*}$ \\
\hline Live & 74 & 11.108 & 12.960 & 1.851 & $.596^{*}$ & $10.395^{*}$ \\
\hline Hybrid & 72 & 10.639 & 12.917 & 2.278 & $.114^{* *}$ & $9.184^{*}$ \\
\hline Online & 78 & 10.641 & 12.256 & 1.615 & $.412^{*}$ & $7.727^{*}$ \\
\hline Nonexperimental sections & 963 & 10.685 & 12.507 & 1.821 & $.446^{*}$ & $29.451^{*}$ \\
\hline $\begin{array}{l}* \mathrm{p}<.000 \\
* * \text { n.s. }\end{array}$ & & & & & \\
\hline
\end{tabular}


less familiar than their peers with the library and information literacy topics before participating in the study.

Clearly, the dramatic improvement in these students' scores demonstrates the value of library instruction in teaching information literacy skills to undergraduates.

\section{Research Question Two: Does the Format of Library Instruction Impact Student Learning Outcomes?}

As noted above and shown in figure 2 , the hybrid group demonstrated the greatest improvement in test performance following instruction. And, in fact, both groups that had contact with a librarian - that is, the live and hybrid groups - scored higher on the final exam than the online group, which received no substantial librarian interaction. To determine if these differences among the experimental groups were significant, however, the researchers conducted a number of additional statistical analyses. Because the study design incorporates three levels of the independent variable (instruction type), a one-way ANOVA was chosen to compare the means of the experimental groups on final exam scores. The analysis revealed a significant difference $(\mathrm{F}=4.477, \mathrm{df}=2, \mathrm{p}=.012)$ in final exam means of the samples. The post-hoc Scheffé multiple comparisons procedure was then conducted to determine where the differences existed. In fact, the Scheffé comparison found significant differences between both the live and online groups $(p=.031)$ and the hybrid and online groups $(p=.048)$. The online group, then, performed significantly lower on the final exam than the other two groups.

The researchers also wanted to determine whether the inclusion of pre-test scores in the analysis of variance would impact these findings. To accomplish this, the researchers chose to conduct an analysis of covariance (ANCOVA), with final exam scores serving as the dependent variable, instruction method as the between-subjects independent variable, and pre-test scores serving as the covariate. According to Cribbie and Jamieson, the use of ANCOVA in a pre-test/post-test design adjusts for variance that occurs within individual subjects, thereby making it more powerful to detect differences that occur as a result of the treatment being studied. ${ }^{25}$ In addition, ANCOVA is useful particularly in post-test analysis where a "ceiling effect" occurs, ${ }^{26}$ as in the case of this study, in which students could not score higher on the final exam than a perfect score of fifteen points. The ANCOVA measure of betweensubjects effects in the current study $(\mathrm{F}=4.103$, $\mathrm{df}=2, \mathrm{p}=.018$ ) indicates that, indeed, significant differences still exist in final exam scores when pre-test scores are taken into account. Post-hoc pairwise comparisons conducted through SPSS, however, reveal a significant 
difference only between the hybrid and online groups ( $p=.023)$; after adjusting for disparities in pre-test performance, the hybrid group scored significantly higher than the online group on the final exam. Interestingly, the post-hoc tests did not measure a significant distinction between the live and online groups, although the live group scored the highest mean of the three samples and performed almost identically to the hybrid group. It may be that a larger sample size would reveal a difference between these groups, but it may also be that the ANCOVA test simply reflects the observation that the hybrid group displayed the largest improvement in test performance of the three samples.

The results of these analyses ultimately suggest that the differences in means displayed by the three instructional groups cannot be attributed to chance but to the pedagogical model by which they received their library instruction.

\section{Research Questions Three and Four:} Does Instruction Method Affect Students' Satisfaction with their Library Instruction? Does Instruction Method Influence Students' Assessment of their own

\section{Research Abilities?}

The pre-test and final exam included additional qualitative questions designed to assess student satisfaction with their library instruction and to measure changes in students' perceptions of their own research skills after they had completed library instruction. To measure student satisfaction with their library instruction experience, the researchers asked students to rate their level of satisfaction on a fivepoint scale (from "very unsatisfied" to "very satisfied"). A chi-square analysis of student responses to the satisfaction question in relation to their instruction type reveals that a significantly lower number of students in the online group reported being "very satisfied" with their library instruction than students in the other two samples. Here again, the hybrid and live groups performed similarly on this question, with 41.9 percent of the live group and 40.3 percent of the hybrid group reporting being "very satisfied" with their library instruction, compared with only 16.7 percent of the online group answering in the same manner. However, when responses are grouped into broader categories of satisfaction ("very unsatisfied or unsatisfied"; "neutral"; and "satisfied or very satisfied"), the chi-square analysis does not reveal any significant variations in satisfaction levels among the three groups; the online group responded positively to their library instruction format ("satisfied or very satisfied") at approximately the same rate as the other two groups. Therefore, the researchers conclude that student satisfaction with each of the instructional models was approximately equal, although students in the online group were, perhaps, not quite as enthusiastic as students in the other two samples.

The researchers also asked students, on both the pre-test and final exam, to evaluate their own research skills on a four-point scale (from "I need a lot of help getting started" to "I am thoroughly able to do research in the library") to determine whether their self-assessment would improve following library instruction. As shown in table 3, prior to instruction the majority of all experimental subjects (64.3 percent) reported being "somewhat able to do research in the library" prior to instruction, with only 14.7 percent reporting that they were "thoroughly able to do research in the library." After receiving library instruction, students' assessment of their own research abilities improved markedly, with 50.4 percent of subjects reporting that they felt "thoroughly able to do research in the library" and only .9 percent of students responding that they still "needed a lot of help getting started." Overall, 52.7 percent of subjects scored themselves higher on the self-assessment of their research skills following library instruction, with 43.3 percent rating themselves the same on both the pre-test and final exam. Chi-square analyses of students' self-assessment responses on 
The Librarian, the Machine, or a Little of Both 339

\begin{tabular}{|c|c|c|c|}
\hline \multicolumn{4}{|c|}{$\begin{array}{c}\text { TABLE } 3 \\
\text { Self-Assessment of Research Skills, All Experimental Groups }\end{array}$} \\
\hline & Pre-test & Final Exam & \multirow{2}{*}{$\begin{array}{l}\text { Percent } \\
\text { Change }\end{array}$} \\
\hline & $N$ (percent of total) & $N$ (percent of total) & \\
\hline I need a lot of help getting started. & $11(4.9 \%)$ & $2(.9 \%)$ & $-4 \%$ \\
\hline I need some help getting started. & $36(16.1 \%)$ & $4(1.8 \%)$ & $-14.3 \%$ \\
\hline $\begin{array}{l}\text { I am somewhat able to do } \\
\text { research in the library. }\end{array}$ & $144(64.3 \%)$ & $105(46.9 \%)$ & $-17.3 \%$ \\
\hline $\begin{array}{l}\text { I am thoroughly able to do } \\
\text { research in the library. }\end{array}$ & $33(14.7 \%)$ & $113(50.4 \%)$ & $+35.7 \%$ \\
\hline
\end{tabular}

the final exam revealed no significant differences by instruction type, nor was there any real distinction in the number of students who rated their self-assessment higher following instruction for any of the groups ( $\mathrm{R}=9.025, \mathrm{p}=.06)$.

Overall, then, the three experimental groups expressed comparable levels of satisfaction with their library instruction experience as well as similar assessments of their own research skills after receiving library instruction.

\section{Discussion}

From this preliminary study of RHT 160 library instruction, the researchers conclude that contact with a librarian is an important component of student learning. The hybrid group showed the greatest improvement in performance, perhaps due to the combination of instructional methods, which likely appeal to diverse learning styles. However, each of the three experimental groups - the live, hybrid, and online pedagogical models-did show definite improvement from their pre-test to final exam scores; in fact, the difference in mean final exam scores of the highest-performing (live) and the lowest-performing (online) groups was less than a single point, or one question. This suggests that online instruction can be effective. Because RHT 160 library instruction focuses on introductory information literacy skills and the mechanics of searching library databases, it may be that many of these topics lend themselves well to both live and online instruction.
A limitation of this study was the relative easiness of the pre-test and final exams. Subjects scored well on the pre-test, answering, on average, almost 70 percent of the questions correctly even before beginning any form of library instruction. The ease of the tests, then, combined with the ceiling effect on the pre-test and final exam, resulted in relatively low levels of variance among the groups, as well as a skewed data distribution. Attempts to normalize the data by transforming variables yielded a more normal distribution but did not produce different statistical results than described in this paper. It should be noted, too, that ANOVA is a robust test in the face of minor departures from normality ${ }^{27}$ and the ANCOVA test mitigates skewness caused by the ceiling effect present in this study. Nonparametric tests run on the data also revealed the same results. In addition, the results of this study support what is both revealed graphically (see figure 2) and theorized by librarians at Oakland University - that librarian contact is a valuable part of information literacy instruction. Therefore, the researchers are confident in the validity of these preliminary results.

\section{Benefits of Course Management Software}

The library has gained many advantages in using the WebCT course management package for library instruction. Of primary value is the software's data storage capability through its integrated grade book, which allows librarians to download and analyze student results to assess 
learning. Another benefit of offering the instruction modules in WebCT is that, conceptually at least, library instruction is more fully integrated into students' other RHT 160 assignments; the presence of the library instruction icon alongside class materials in their online course environment may encourage students to approach library instruction in a more serious manner. And because many Oakland students are required in other classes to use WebCT, there is often no software learning curve involved in completing the library instruction modules and tests. Finally, although the librarians at Oakland have had to adapt library instruction materials for use in WebCT, this has resulted in a more flexible online instruction program. The library tutorials are housed on the library's server, rather than in WebCT, to facilitate updates of content. ${ }^{28}$ Because of this, each tutorial is portable and can be easily adapted for other courses. For example, one of the researchers has adapted the basic RHT 160 FirstSearch tutorial for use in an online nursing class to teach students how to use CINAHL, a health sciences database available through FirstSearch.

\section{Future Plans}

During the course of this study, subjects assigned to the online group provided informal feedback about their experiences in completing the WebCT-based tutorials. Overall, students found the experience positive, although they wanted the tutorials to be "flashier," incorporating more interactivity and visual interest to enhance their online experience. Oakland will, in the near future, move away from WebCT courseware as a result of the merger of Blackboard and WebCT. This transition will provide an excellent opportunity to overhaul the online instructional modules for RHT 160 in response to student comments.

In brief discussions with the Rhetoric faculty participating in the study, the instructors expressed their reservations with the all-online instruction format. Lack of student motivation plays a large role in their concerns, as does lack of contact with a librarian. Because progress through the online tutorials cannot be tracked, students may not actually be reading the tutorials before attempting the quizzes; unfortunately, WebCT offers no effective way to make quizzes available to students based on tutorial completion. As a result, it is impossible to determine if students are actively working through the tutorials. However, it is also difficult to ensure that students are actively engaged when they are receiving live instruction. It should be noted that this study did not attempt to measure the intangible benefits of classroom contact with a librarian, such as a greater comfort level in visiting the library and willingness to ask for assistance. The researchers will take into account RHT faculty concerns in any changes made to the RHT 160 library instruction program.

This study currently is being replicated. For this second phase, the study incorporates a larger sample size, and the pre-test/final exam instrument has been revised to increase difficulty and better reflect what is being taught both online and in the classroom. Although data have not yet been analyzed, the researchers believe that these changes will increase variance and make an analysis of variance more robust. Other planned enhancements to the study include an exploration of students' attitudes toward the three library instruction pedagogical models and a review of subjects' final paper bibliographies to explore whether instruction method impacts the quality of sources selected by students. In addition, the researchers will conduct a question-by-question analysis of both pre-test and final exam results to investigate whether some information literacy topics are better suited to online instruction; with the transfer of additional content into the online environment, more in-class time could be allotted to advanced topics in information literacy instruction. The collective results of these endeavors will guide the revision of instructional content-whether taught online or in 
the classroom - for Oakland University's RHT 160 library instruction program.

\section{Concluding Remarks}

In the first iteration of the library's WebCTbased hybrid model in 2001, some fairly advanced content-such as a module on keyword searching techniques-was offered online. From the observations of librarians over the course of an academic year, however, it did not appear that students grasped these difficult concepts when delivered electronically; therefore, in the following year this content was once again taught face-to-face by librarians. The empirical results of this study support the informal observations of classroom faculty and librarians that in-person contact between librarians and students significantly enhances student understanding of complex information literacy topics. Also, these results strengthen the findings of other studies noted above that argue for the intangible benefits that students receive from face-to-face instruction.

Unfortunately, like most institutions, Kresge Library faces an increasing demand for instruction each year without an equivalent increase in library faculty; as a result, resource constraints may force the library faculty to move even more instructional content online. Further, the university administration is strongly encouraging the development of more online courses, which will create a need for additional online library instruction modules. Consequently, the researchers expect that Kresge Library's online presence will have to expand rapidly in the next few years. Because of this, librarians must devise new ways of connecting students with the physical space of the library in this increasingly anonymous, technology-driven world.

The findings of this preliminary study suggest that online instruction should be but one component of a comprehensive information literacy program, which must also include librarian-student interaction. Using a hybrid instructional model, librarians can address multiple learning styles, engage students with the latest technology, respond to external pressures to move into an online teaching environment, and still maintain the physical contact that is vital to student learning.

\section{Notes}

1. Oakland University Office of Institutional Research and Assessment, "Fall Headcount \& FYES 1959-2005," Oakland University. Available online from https://www2.oakland.edu/secure/ oira/FYES1.htm. [Accessed 28 March 2006].

2. For examples of libraries using CAI to help manage teaching demand, see Elaine Anderson Jayne, Judith M. Arnold, and Patricia Fravel Vander Meer, "Casting a Broad Net: The Use of Web-based Tutorials for Library Instruction," in The Eighth Off-Campus Library Services Conference Proceedings Held in Providence, Rhode Island 22-24 April 1998, edited by P. Steven Thomas and Maryhelen Jones (Mount Pleasant, Mich.: Central Michigan University, 1998), 197-205; Elizabeth W. Kraemer, "Developing the Online Learning Environment: The Pros and Cons of Using WebCT for Library Instruction," Information Technology and Libraries 22 (June 2003): 87-92; Stephanie Michel, "What Do They Really Think? Assessing Student and Faculty Perspectives of a Web-based Tutorial to Library Research," College \& Research Libraries 62 (July 2001): 317-32.

3. Lana Dixon, Marie Garrett, Rita Smith, and Alan Wallace, "Building Library Skills: Computer-Assisted Instruction for Undergraduates," Research Strategies 13, no. 4 (1995): 198.

4. For examples, see Carol Anne Germain, Trudi E. Jacobson, and Sue A. Kaczor, "A Comparison of the Effectiveness of Presentation Formats for Instruction: Teaching First-Year Students," College E Research Libraries 61 (Jan. 2000): 65-72; Lucy Holman, "A Comparison of Computer-Assisted Instruction and Classroom Bibliographic Instruction," Reference E User Services Quarterly 40 (Fall 2000): 53-60; Neosha Mackey and others, "Teaching with HyperCard in Place of a Textbook," Computers in Libraries 12 (Oct. 1992): 22-25.

5. Joan Kaplowitz and Janice Contini, "Computer-Assisted Instruction: Is It an Option for Bibliographic Instruction in Large Undergraduate Survey Classes?" College E Research Libraries 59 (Jan. 1998): 20.

6. Jayne, Arnold, and Vander Meer, "Casting a Broad Net"; Michel, "What Do They Really 
Think?"; Don Tapscott, Growing Up Digital: The Rise of the Net Generation (New York: McGraw-Hill, 1998).

7. Judith M. Pask, "Computer-Assisted Instruction for Basic Library Skills," Library Software Review 7 (Feb. 1988): 6-11.

8. Holman, "A Comparison of Computer-Assisted Instruction"; Kaplowitz and Contini, "Computer-Assisted Instruction"; Pierina Parise, "Information Power Goes Online: Teaching Information Literacy to Distance Learners," Reference Services Review 26 (Fall/Winter 1998): 51-52, 60; Pask, "Computer-Assisted Instruction for Basic Library Skills"; Jeffrey M. Wilhite, "Internet Versus Live: Assessment of Government Documents Bibliographic Instruction," Journal of Government Information 30, no. 5/6 (2004): 561-74.

9. Tapscott, Growing Up Digital, 139.

10. Ann Turner, "Computer-Assisted Instruction in Academic Libraries," The Journal of Academic Librarianship 15 (Jan. 1990): 353.

11. Kraemer, "Developing the Online Learning Environment."

12. Holman, "A Comparison of Computer-Assisted Instruction."

13. Germain, Jacobson, and Kaczor, "A Comparison of the Effectiveness of Presentation Formats for Instruction"; Pask, "Computer-Assisted Instruction for Basic Library Skills."

14. James Nichols, Barbara Shaffer, and Karen Shockney, "Changing the Face of Instruction: Is Online or In-Class More Effective?," College \& Research Libraries 64 (Sept. 2003): 385.

15. For examples, see Getty and others, "Using Courseware to Deliver Library Instruction via the Web"; Holman, "A Comparison of Computer-Assisted Instruction"; Kraemer, "Developing the Online Learning Environment"; Michel, "What Do They Really Think?"; Jo Parker and others, "Is a standalone IL course useful?," Library E Information Update 4 (Jan./Feb. 2005): 34-35.

16. Marion Churkovich and Christine Oughtred, "Can an Online Tutorial Pass the Test for Library Instruction? An Evaluation and Comparison of Library Skills Instruction Methods for First Year Students at Deakin University," Australian Academic E Research Libraries 33 (March 2002): 25-38.

17. Kaplowitz and Contini, "Computer-Assisted Instruction"; Denise Madland and Marian A. Smith, "Computer-Assisted Instruction for Teaching Conceptual Library Skills to Remedial Students," Research Strategies 6, no. 2 (1988): 52-64.

18. Germain, Jacobson, and Kaczor, "A Comparison of the Effectiveness of Presentation Formats for Instruction."

19. Nichols, Shaffer, and Shockey, "Changing the Face of Instruction."

20. Churkovich and Oughtred, "Can an Online Tutorial Pass the Test for Library Instruction?" 34-35.

21. Ibid.

22. Linda B. Alexander and Robert C. Smith, "Research Findings of a Library Skills Instruction Web Course," portal: Libraries and the Academy 1, no. 3 (2001): 309-28.

23. Many past studies have relied on a two-group design to measure the effectiveness of different instructional methods. Notable exceptions include: Holman, "A Comparison of Computer-Assisted Instruction," which employed a three-group design to measure student performance: CAI, in-class instruction, and a noninstructional control group; Wilhite, "Internet Versus Live," in which a study of three student groups - online, live, and a noninstructional control-was used to assess the effectiveness of online government documents library instruction; and William A. Orme, "A Study of the Residual Impact of the Texas Information Literacy Tutorial on the Information-Seeking Ability of First Year College Students," College E Research Libraries 65 (May 2004): 202-15, in which four cohort groups were used to compare student achievement: noninstructional control, Web-based instruction, classroom instruction, and Web-based plus classroom instruction.

24. For examples of these results, see Alexander and Smith, "Research Findings of a Library Skills Instruction Web Course"; Churkovich and Oughtred, "Can an Online Tutorial Pass the Test for Library Instruction?"; Dorothy F. Davis, "A Comparison of Instruction Methods on CDROM Databases," Research Strategies 11, no. 3 (1993): 156-63; Germain, Jacobson, and Kaczor, "A Comparison of the Effectiveness of Presentation Formats for Instruction"; Mackey and others, "Teaching with HyperCard in Place of a Textbook"; Orme, "A Study of the Residual Impact of the Texas Information Literacy Tutorial."

25. Robert A. Cribbie and John Jamieson, "Decreases in Posttest Variance and the Measurement of Change," Methods of Psychological Research Online v. 9, no. 1 (2004): 37-55. Available online from www.mpr-online.de. [Accessed 1 March 2006].

26. Ibid.

27. Geoffrey Keppel and William H. Saufley, Jr., Introduction to Design and Analysis (New York: W.H. Freeman and Company, 1980), 97.

28. For an explanation of the complexity of making changes in WebCT, see Kraemer, "Developing the Online Learning Environment," 89. 